\title{
AS DIRETRIZES DA EDUCAÇÃO ESPECIAL E INCLUSIVA NAS ESCOLAS RIBEIRINHAS
}

\section{ARTIGO DE REVISÃO}

FERREIRA, Arnaldo Machado ${ }^{1}$

SANGALLI, Andréia ${ }^{2}$

FERREIRA, Arnaldo Machado. SANGALLI, Andréia. As diretrizes da Educação Especial e Inclusiva nas escolas ribeirinhas. Revista Científica Multidisciplinar Núcleo do Conhecimento. Ano 05, Ed. 08, Vol. 07, pp. 53-70. Agosto de 2020. ISSN: 2448-0959, Link de acesso: https://www.nucleodoconhecimento.com.br/educacao/escolas-ribeirinhas

\section{RESUMO}

A temática central deste estudo gira em torno da abordagem histórica da Educação Especial e Educação do campo, mais especificamente sob o paradigma da realidade ribeirinha enquanto espaço ancorado na sua realidade social. $O$ objetivo que fundamentou sua elaboração foi analisar e compreender os aspectos contextuais históricos dessas duas modalidades de ensino visando refletir criticamente sobre o processo de inclusão educacional para as pessoas com deficiência. Nesse sentido, a situação problema surge quando nos defrontamos com situações de carência no que concerne a oferta e organização de um ensino que atendam às necessidades educacionais que as pessoas com deficiência que vivem e estudam nas escolas do

\footnotetext{
${ }^{1}$ Mestrando em Educação e Territorialidade - Especialista em PROEJA (Educação Profissional Integrada à modalidade de Educação de Jovens e Adultos) - Especialista em Atendimento Educacional especializado (AEE) - Graduando em Letras-Libras Licenciado em Pedagogia.

2 Orientadora. Doutorado em Agronomia. Mestrado em Agronomia. Graduação em Ciências Biológicas.
} 
campo ribeirinho vêm enfrentando ao longo da história. Amparados nas concepções conceituais de Mazzota (2005), Caiado (2015), Mantoan (2003), Corrêa (2019) dentre outros autores que nos permitiram conhecer os aspectos contextuais dessas duas modalidades de ensino no Brasil. Como proposta metodológica foi realizada uma pesquisa numa abordagem qualitativa e análise do tipo bibliográfico com levantamento de artigos, livros e dissertações sobre as concepções do contexto histórico compreendendo as diversas manifestações que abordam diferentes perspectivas da interface entre Educação Especial e Educação do campo sob uma perspectiva inclusiva. Com o estudo, pretendemos despertar uma análise crítica sobre o processo de inclusão efetivo para os deficientes que estudam nas escolas ribeirinhas, contribuindo para o debate e a ampliação das reflexões a cerca da importância de considerar as necessidades e peculiaridades dessa clientela assegurando uma equidade educacional.

Palavras-chave: Educação Especial, escolas ribeirinhas, inclusão escolar.

\section{INTRODUÇÃO}

Este artigo é um ensaio bibliográfico da minha dissertação de mestrado do Programa de pós-graduação em Educação e Territorialidade da Faculdade Intercultural Indígena (FAIND) vinculada à Universidade Federal da Grande Dourados (UFGD) MS, que consiste na exposição das ideias principais da minha pesquisa monográfica, buscando reflexões interdisciplinares da Educação especial e da Educação do Campo, sem, contudo, explorar o tema da referida pesquisa de forma exaustiva.

Pretendemos despertar algumas reflexões ao analisar de forma crítica os debates que perpassam as discussões destinadas à educação das pessoas com deficiência que inicia no Brasil no final dos anos cinquenta e início do século $X X$, bem como da educação do campo no sentido da promoção de direitos educacionais, propondo-se a verificar se as diretrizes da educação inclusiva abrange a população deficiente do campo ribeirinho. Ressalta-se nesse ensaio a relevância de considerar as necessidades e peculiaridades dessa clientela assegurando uma equidade educacional de maneira efetiva. "Equidade implica educar de acordo com as 
diferenças e necessidades individuais, sem que as condições econômicas, demográficas, geográficas, étnicas ou de gênero acarretem um impedimento à aprendizagem". (UNESCO, 2019)

Uma escola, ao ser considerada como instituição inclusiva, deve ser o agente transformador da comunidade, atendendo a todas as especificidades dos alunos, especificamente dos alunos com necessidades educativas especiais que nessa pesquisa se perpassa na educação do campo ribeirinho evitando uma dupla exclusão escolar.

Neste viés, queremos estabelecer um entrelaçamento entre Educação Especial com as concepções da Educação do Campo numa perspectiva inclusiva e efetivação de direitos. Considerando a complexidade que gira em torno do processo da inclusão, e que a mesma é hoje uma realidade social, seria incoerente deixar a responsabilidade da inclusão somente para os aspectos legais, e a elas atribuir a responsabilidade da incoerência que vem ocorrendo na construção de uma sociedade inclusiva.

Em conformidade com o objeto de estudo e com a questão acima referidos, o objetivo que fundamentou sua elaboração foi analisar e compreender os aspectos contextuais históricos dessas duas modalidades de ensino visando refletir criticamente sobre o processo de inclusão educacional para as pessoas com deficiência que vivem na região ribeirinha. Como objetivos específicos pretende-se conter resultados das diretrizes do processo inclusivo e conhecer a realidade social dos sujeitos da educação especial nas escolas ribeirinhas.

Nesse sentido e em acordo com o objetivo geral, a situação problema surge quando nos defrontamos com situações de exclusão no que concerne a oferta e organização de um ensino que atendam as necessidades educacionais e individuais que as pessoas com deficiência que vivem e estudam no campo vem enfrentando ao longo da historia.

Com base nos preceitos legais e nos propósitos dessa pesquisa, nos amparamos nas concepções conceituais de Mazzota (2005); Caiado (2015); Mantoan (2003) e Corrêa 
(2019), dentre outros que nos propiciarão elementos teóricos e que nos permitirão conhecermos os aspectos contextuais dessas duas modalidades de ensino no Brasil.

Como proposta metodológica foi feita uma pesquisa do tipo bibliográfica com levantamento de artigos de periódicos, livros, teses e dissertações sobre as concepções do contexto histórico compreendendo as diversas manifestações que abordam diferentes perspectivas interdisciplinar da Educação Especial e Educação do Campo sob uma perspectiva inclusiva e toda essa gama de abordagens que contribui para o debate e a ampliação das reflexões a partir das concepções exploradas que nos propiciarão elementos teóricos para nossa pesquisa.

Para Lakatos e Marconi (2003) a pesquisa bibliográfica compreende oito fases distintas, dentre as quais, a interpretação exige a comprovação ou refutação das hipóteses, no entanto deve-se considerar "que os dados por si só nada dizem, é preciso que o cientista os interprete, isto é, seja capaz de expor seu verdadeiro significado e compreender as ilações mais amplas que podem conter."(p. 49)

Pretendemos nesse artigo construir diálogos para despertar uma análise crítica sobre o processo de inclusão de maneira efetiva para os deficientes que estudam nas escolas ribeirinhas, contribuindo para o debate e a ampliação das reflexões acerca da importância de considerar as necessidades e peculiaridades dessa clientela assegurando uma equidade educacional. Ressaltando-se a importância da proposta desafiadora da nossa pesquisa que é motivado em torno de desenvolver um estudo que apresente um pouco da realidade das pessoas com deficiência e que estão inseridos nas escolas do campo (zona ribeirinha), uma vez que "educação especial e educação do campo são consideradas direitos sociais" (CAIADO; MELLETTI, 2011).

\section{SÍNTESE HISTÓRICA DA EDUCAÇÃO ESPECIAL E INCLUSIVA}

Ao realizar um apanhado histórico da educação especial observamos que diferentes atitudes foram tomadas ao longo dos tempos em relação às pessoas com deficiências, e que durante séculos, a ignorância, o medo, o preconceito e os tabus foram 
responsáveis por manterem crianças, jovens e adultos público da educação especial, afastadas do convívio social todas as pessoas com deficiência.

Há muito tempo as pessoas com deficiências, foram deixadas a margens do processo educativo em várias sociedades sendo em muitos casos considerados loucos ou criaturas amaldiçoadas por Deus, o que perdurou até fins da idade média.

Muitas mudanças vieram acontecendo nas últimas décadas nos aspectos legais e políticos da educação especial. Essas mudanças ocorreram a nível nacional e internacional, através de Declarações, Convenções, Resoluções e Leis, os mesmos surgiram com o intuito de assegurar os direitos das pessoas com deficiência. Diante disso, serão discutidos a seguir, documentos orientadores no âmbito internacional e nacional, respectivamente.

Os documentos legais prescrevem que o deficiente é aquele que apresenta impedimento de longo prazo com limitações físicas, sensoriais e intelectuais, considerado pela sociedade como coitadinhos e incapazes de assumirem um papel socialmente útil, tendo sua participação obstruída na sociedade e preteridos pelo sistema de ensino e social. (LEI № 13.146, DE 6 DE JULHO DE 2015).

De acordo com Mazzota (2005), a Educação Especial no Brasil é uma modalidade de ensino que apresenta um caráter assistencialista aos deficientes, que por sinal nem sempre apresentou a mesma configuração no decorrer da história educacional brasileira. Isso se confirma pelas medidas educacionais e decretos legais que foram ganhando espaço, mas principalmente pela proliferação das políticas e práticas de inclusão que foram sendo inseridas nos ambientes escolares para garantia de acesso e permanência dos alunos que enfrentam barreiras no processo de escolarização, mas que tem sido alvo de inúmeros estudos, discussões e mudanças.

A visibilidade da educação especial vem sendo percebida nas últimas décadas através da forma da oferta do ensino educacional no país. Porém, percebemos que, apesar das políticas educacionais atuais advogarem a favor da inclusão escolar dos alunos que apresentam deficiência, sua organização tem enfrentado dificuldades 
mesmo no âmbito urbano que possuem todos os instrumentos e equipamentos necessários para sua implementação, quanto mais no campo, que apresentam questões inerentes a sua realidade, sendo que a maioria dos docentes enfrentam dificuldades e não se sentem preparados ou com formação adequada para lidar com o diferente.

A inclusão deve promover a interação e acolher a todos, sem exceção, no sistema escolar, com a garantia de equidade de acesso, bem como de conteúdos e metodologias que respeitem a especificidade dos educandos, sejam eles do campo ou cidade, com deficiências ou sem deficiências, para que possam alcançar a autonomia e a cidadania com o direito do respeito à diversidade (CAMACHO; VIEIRA, 2018, p. 445).

Atualmente o movimento inclusivo no Brasil, vem sendo cada vez mais intensificado, porém ainda não se leva em consideração as limitações e especificidade de cada sujeito. Nas pesquisas referentes ao tema da educação especial e inclusiva como objeto de estudo, não fica restrito apenas ao contexto educacional na área urbana, expandindo-se para investigações na área do campo, e mais especificamente na região ribeirinha, que apresentam peculiaridades próprias.

O desenvolvimento de debates, encontros, seminários, sobre essa temática aponta para a importância de descobrirmos mecanismos práticos que atendam as metas da inclusão e logo permita aos profissionais enfrentar o desafio maior que ela nos impõe: trabalhar com a diversidade humana (RIBEIRO, 2001, p. 33).

Segundo Mazzota (2005) a modalidade da educação especial foi inspirada nas experiências da Europa onde se deram os primeiros movimentos de atendimento aos deficientes, e somente a partir do século XX começou a exercer impacto no Brasil. Porém só se expandiu com mais força a partir dos anos 90, principalmente em decorrência da Declaração de Salamanca que resultou de uma Conferência Mundial de Educação Especial, realizada na cidade de Salamanca, Espanha. Nesta conferência foi reafirmado o direito à educação de cada indivíduo o que já havia sido proclamado na Declaração Universal dos Direitos Humanos (1948) e fortemente reconfirmado na Conferência Mundial de Educação para Todos.

A Declaração de Salamanca parte do pressuposto que as escolas regulares devem: 
...acomodar todas as crianças independente de suas condições físicas, intelectuais, sociais, emocionais, linguísticas ou outras... Escolas devem buscar formas de educar tais crianças bem - sucessivamente, incluindo aquelas que possuam desvantagens severas.... (1994, p.4).

Em 20 de dezembro de 1996 foi sancionado a LDB no 9.394, a qual utilizou o capítulo $\checkmark$ especificamente para a educação especial. Em seu artigo 58 conceitua a educação especial como "modalidade de educação escolar oferecida preferencialmente na rede regular de ensino, para educandos com deficiência".

No parágrafo $1^{\circ}$ do mesmo artigo estabelece que "haverá, quando necessário, serviços de apoio especializados". O artigo 59 determina que "os sistemas de ensino assegurarão aos portadores de necessidades especiais", [...] "currículo, métodos, técnicas, recursos educativos e organização específica para atender suas necessidades". Também assegurarão professores com especialização adequada em nível médio ou superior para atendimento especializado, bem como professores do ensino regular, capacitado para a integração desses educandos, na classe comum.

Em 1999 acontece a Convenção da Guatemala que foi uma Convenção Interamericana para a Eliminação de Todas as Formas de Discriminação contra a Pessoa Portadora de Deficiência, promulgada no Brasil pelo decreto ํㅜ․ 3.956/2001, onde afirma que as pessoas com deficiência têm os mesmos direitos humanos e liberdades fundamentais que as demais pessoas, definindo como discriminação toda diferenciação ou exclusão que possa impedir ou anular o exercício dos direitos humanos e de suas liberdades fundamentais.

Ao externarmos todos os aspectos legais até os dias atuais percebe-se que novos rumos ligados a conquista de um pensamento voltado a inclusão começaram a se firmar no Brasil e que De lá pra cá outras todas os documentos, leis e decretos que primaram-se por mudanças nos princípios da educação inclusiva na sociedade brasileira, tendo como princípio viabilizar políticas públicas viessem atingir a qualidade social no espaço escolar.

Com o intuito de relembrar o caminho da construção legal dos deficientes do ambiente escolar destacamos: a Declaração Universal dos Direitos Humanos (1948); o Pacto 
Internacional dos Direitos Econômicos, Sociais e Culturais (1966); a Convenção sobre os Direitos da Criança (1989); a Conferência Mundial sobre Educação para Todos (1990); a Convenção sobre os Direitos das Pessoas com Deficiência (2006); o Estatuto da Criança e do Adolescente (1990); a Declaração de Salamanca (1994); ou mesmo, referir-me à Constituição Federal de 1988 e às Diretrizes e Bases da Educação Nacional - Lei n. 9.394/96 (1996); O Plano Nacional de Educação - PNE, Lei 10.172/2001, objetivando estimular a construção de escolas inclusivas que garantisse $\mathrm{O}$ atendimento à diversidade, através de objetivos e metas que favoreceriam o atendimento às necessidades educacionais dos alunos especiais; $A$ Lei no10436/02 que reconhece a Língua Brasileira de Sinais -LIBRAS- como meio legal de expressão e comunicação, apoiando o uso e difusão, bem como a inclusão na grade curricular dos cursos de formação de professores e fonoaudiologia; A Portaria no 2678/02 aprova diretrizes e normas para o uso, o ensino, a produção e a difusão do Sistema Braile, compreendendo o projeto da gráfica Braile para a Língua Portuguesa e a recomendação para o seu uso em todo o território nacional; A Lei de Acessibilidade - MEC/SEESP, 10.098/2000 regulamentada em 2004 por decreto-lei que trata da acessibilidade ao meio físico em edifícios, vias públicas, mobiliário, equipamentos urbanos etc; Ou ainda em 2007 temos o Plano de Aceleração do Crescimento onde é lançado o Plano de Desenvolvimento da Educação- PDE que busca superar a oposição entre a educação regular e educação especial.

Até que em Janeiro de 2008 o Ministério da Educação/Secretaria de Educação Especial apresenta a Política Nacional de Educação Especial na Perspectiva da Educação Inclusiva que possui como objetivos e diretrizes ajudar o bom andamento do trabalho educacional do ensino regular e especializado, assegurando acesso, a participação e a aprendizagem dos alunos público alvo da Educação especial.

Após a Política Nacional de Educação Especial na Perspectiva da Educação Inclusiva de 2008, justifica a resolução 04/2009 CNE-CEB (BRASIL, 2009) institui as diretrizes operacionais para o Atendimento Educacional Especializado (AEE) na educação básica, modalidade educação especial. O AEE caracteriza por um conjunto de recursos e serviços educacionais especiais organizados para apoiar, suplementar e, 
em alguns casos, substituir os serviços educacionais comuns, de modo a garantir a educação formal dos educandos que apresentem necessidades de impedimentos nas funções e nas estruturas do corpo, que de acordo com a LBI no 13.146, de 6 de julho de 2015, que Institui a Lei Brasileira de Inclusão da Pessoa com Deficiência (Estatuto da Pessoa com Deficiência) são as pessoas que apresentam limitação no desempenho de atividades, e/ou na restrição de participação.

Sendo que a Política Nacional de Educação Especial na Perspectiva da Educação Inclusiva (2008) aponta "que as dificuldades enfrentadas nos sistemas de ensino evidenciam a necessidade de confrontar as práticas discriminatórias e criar alternativas para superá-las".

Desse modo, o amparo da legislação seria um dos fatores primordiais para que se efetivem as mudanças necessárias no âmbito educacional, assim como em toda a sociedade para atender as pessoas com necessidades educacionais especiais.

Diante dos documentos apresentados no âmbito internacional e nacional, notifica-se de extrema importância a garantia dos direitos das pessoas com deficiência, mas para que estes direitos sejam garantidos é preciso que seja realizada sua efetivação em todos os aspectos, tanto político, quanto educacional e cultural, e também de ressignificação docente, fazendo com que cada documento apresentado até hoje trazem garantias de educação para todos, estabelecendo que todas as pessoas com deficiência tenham acesso ao mesmo ambiente escolar frequentado por todas as demais crianças, seja no espaço urbano ou do campo.

\section{A EDUCAÇÃO DO CAMPO NA ESCOLA RIBEIRINHA}

"Pensar o campo como território significa compreendê-lo como espaço de vida, ou como um tipo de espaço geográfico onde se realizam todas as dimensões da existência humana". (FERNANDES; MOLINA 2006, p. 29, 30).

Consubstanciado num parâmetro educativo, o contexto escolar ribeirinho é concebido enquanto uma dimensão institucional pedagógica e sócio-político-cultural. Para tanto, 
é fundamental que a escola conheça a realidade social da comunidade que atende e, dessa forma, poder atender às necessidades dessa comunidade, cumprindo uma de suas funções sociais.

A educação do Campo, tratada como educação rural na legislação brasileira, tem um significado que incorpora os espaços da floresta, da pecuária, das minas e da agricultura, mas os ultrapassa ao acolher em si os espaços pesqueiros, caiçaras, ribeirinhos e extrativistas. O campo, nesse sentido, mais do que um perímetro não-urbano, é um campo de possibilidades que dinamizam a ligação dos seres humanos com a própria produção das condições da existência social e com as realizações da sociedade humana. (BRASIL, 2012, p. 07)

Para conceituar educação do campo considerando os saberes do ambiente que o cerca, nos apropriamos das palavras proposta por Isabel Brasil Pereira Caldart de que "O território camponês é o espaço de vida do camponês. É o lugar ou os lugares onde uma enorme diversidade de culturas camponesas constrói sua existência". (CALDART, 2012, p. 746).

A educação do campo destina-se à população rural como: agricultores familiares, extrativistas, pescadores artesanais, ribeirinhos, assentados e acampados da Reforma Agrária, quilombolas, caiçaras, indígenas e outros. Tem como objetivo a universalização do acesso, da permanência e do sucesso escolar com qualidade em todo o nível da Educação Básica. Assim como, estar vinculada às peculiaridades da vida rural de cada região do país (BRASIL, 1996; 2008b). (CAIADO; MELETTI, 2011, p. 95).

“...A educação sempre foi inacessível para estas populações excluídas que não ultrapassavam, em sua maioria, as séries iniciais do ensino fundamental, por isso, há ainda um grande número de analfabetos no campo. (CAMACHO; VIEIRA, 2018, p. 445). Sendo assim, ressalta-se a construção de uma política de educação do campo se dá em virtude do reconhecimento da enorme dívida do país com os povos do campo no que diz respeito ao direito à educação. (BRASIL, 2012).

O ministério da educação, o conselho nacional de educação e a câmara de educação básica na resolução № 1, de 3 de abril de 2002, institui Diretrizes Operacionais para a Educação Básica nas Escolas do Campo, e esclarece no parágrafo único que "A identidade da escola do campo é definida pela sua vinculação às questões inerentes 
à sua realidade, ancorando-se na temporalidade e saberes próprios dos estudantes..." (BRASIL, 2012, p 33).

A partir das características enfrentadas no campo que se apresentam através de problemas socioeconômicos e educacionais na busca de soluções por parte dos movimentos sócio territoriais camponeses, por disputas e conflitos de territorialidades, pelo modo de vida camponês, pela identidade territorial camponesa, pelos movimentos sócio territoriais e etc, é que se percebem as semelhanças e singularidades com a educação especial que também enfrenta um contexto de contradições e lutas vividas no âmbito educacional.

campo se difere da zona urbana em vários aspectos. E em se tratando se região ribeirinha as escolas apresentam questões singulares: estruturais, acessibilidade arquitetônica, forma de vida e etc. "Os povos ribeirinhos habitam o interior da Amazônia e vivem às margens de rios, lagos e igarapés" (LOBATO; DAVIS, 2019, p. 176)

Nos estudos voltados para educação do campo o professor Rodrigo Simão Camacho afirma que:

O modo de vida e a identidade territorial camponesa são partes integrantes do projeto educativo dos camponeses. Logo, entender o território camponês é de suma importância para a construção de uma concepção teórica-política-ideológica de Educação do Campo adequada a lógica material e simbólica de reprodução da territorialidade do campesinato, e que contribua em seu processo de resistência política e cultural. (CAMACHO, 2019, p. 39)

Ao conceituar o que é campo Camacho (2019) logo faz uma relação com a educação propondo que "...À Educação do Campo, portanto, cabe construir uma pedagogia a partir das especificidades da territorialidade do campesinato que está inserido no interior da totalidade das relações sociais sob o modo de produção capitalista globalizado". (CAMACHO, 2019, p. 40).

A zona ribeirinha enquanto espaço inserido no campo caracteriza-se por peculiaridades composta por rios, igarapés, matas, e que os sujeitos ribeirinhos, assim 
chamados por viverem cercados de águas e utilizarem como transporte barcos, rabetas e canoas, ..."possuem forte relação com sua cultura local, com a diversidade de fauna e flora, características e peculiaridades que são facilmente percebidas no espaço escolar e exigem, como se verá adiante, uma prática pedagógica específica'. (LOBATO; DAVIS, 2019, p. 174)

Esse conceito atenua as discussões e reflexões de que a escola ribeirinha, deve preparar-se nos aspectos físicos e estruturais e adaptar as ações curriculares à sua realidade. Ações pedagógicas que considere desde os aspectos estruturais até o modo de vida dos sujeitos que moram e estudam no campo - escola ribeirinha, buscando alcançar o respeito às diferenças e oportunizando os alunos com deficiência na escola do campo à possibilidade de um aprendizado melhor e significativo para interagir em meio à comunidade o qual convive.

Um dos aspectos pedagógicos da escola é desenvolver a sua função social compensatória onde a escola do campo dessas comunidades tradicionais, deve valorizar e respeitar a realidade e as formas de viver e conviver com o campo enquanto instituição social e que deve atenuar, em parte, os efeitos da desigualdade. Esse aspecto enfatizam duas outras vertentes: o desafio de reconhecer o sujeito ribeirinho nas práticas pedagógicas e o de garantir acesso, permanência e sucesso escolar das pessoas com deficiência nas escolas da zona ribeirinha.

\section{A EDUCAÇÃO ESPECIAL NA ESCOLA DO CAMPO SOB O PARADIGMA DA EDUCAÇÃO INCLUSIVA}

Percebe-se que atualmente a escola está inserida em um espaço de trocas de experiências, convivências e mudanças, e um dos papeis da escola é estabelecer ou promover um ambiente que evite a segregação ou exclusão dos alunos independente de suas peculiaridades físicas, cognitivas os sociais, mediando e executando condições apropriadas para o ser humano se desenvolver e aprender, independente do local que está inserido. 
Porém, percebemos que de maneira interdisciplinar, tanto a educação especial quanto a educação do campo apresentam incoerências na sua oferta diante das peculiaridades em que se apresentam. Sendo assim, será que essas duas modalidades de ensino contemplam as diretrizes da educação inclusiva?

Segundo a Lei Brasileira de Inclusão da pessoa com deficiência deve ser assegurada a promoção de condições de igualdades, o exercício dos direitos e das liberdades fundamentais para as pessoas com qualquer tipo de deficiência, visando a inclusão social e a cidadania do sujeito.

De acordo com a Lei Brasileira de Inclusão da Pessoa com Deficiência (LBI), nº 13.146, DE 6 de julho de 2015 no seu capítulo IV, sobre direito à educação, diz que:

Art. 27. A educação constitui direito da pessoa com deficiência, assegurados sistema educacional inclusivo em todos os níveis e aprendizado ao longo de toda a vida, de forma a alcançar o máximo desenvolvimento possível de seus talentos e habilidades físicas, sensoriais, intelectuais e sociais, segundo suas características, interesses e necessidades de aprendizagem. (LBI, 2015).

$\mathrm{Na}$ perspectiva da educação inclusiva, a educação especial passa a fazer parte integrante da escola como proposta pedagógica. Qualquer indivíduo impedido fisicamente, mentalmente, intelectualmente da sua participação no ambiente escolar passa a fazer parte de um público diferenciado no que tange ao acesso para a aquisição da aprendizagem. É necessário que a escola crie metodologias pedagógicas que transforme o processo ensino aprendizagem num momento significativo, prazeroso e inclusivo.

Ao falar de equidade educacional estamos tratando de um uma pedagogia que lance um olhar humanizado para cada sujeito. Freire (1996) afirma que uma educação autêntica promove a capacidade de conviver humanamente, isto é, onde os sujeitos sejam capazes de relacionar-se, construir-se e desenvolverem-se na interação com os outros, pois não nascemos para o isolamento, sim para a fraternidade.

"O conceito de campo como espaço de vida é multidimensional e nos possibilita leituras e políticas mais amplas do que o conceito de campo ou de rural somente como 
espaço de produção de mercadorias". (FERNANDES; MOLINA, 2005, p. 29). O autor Miguel Arroyo (2003) sustenta esse conceito acima colocado quando faz o seguinte questionamento "Como pensar currículos, conteúdos e metodologias, como formular políticas e planejar programas educativos sem incorporar os estreitos vínculos entre as condições em que os educandos reproduzem suas existências e seus aprendizados humanos?" (ARROYO, 2003, p. 33).

A Declaração de Salamanca vem dar suporte de acessibilidade aos educandos com deficiência aos espaços escolares, mas a mesma não garante, que de fato, os educandos possam ser incluídos em sala de aula regular, pois, para além disso, vivemos em uma sociedade organizada nos pressupostos do sistema capitalista que produz a exclusão e a segregação das pessoas com e sem deficiência, além de manter os educadores com intensas car gas de trabalho nos espaços escolares dificultando 0 seu amadurecimento teórico a aquisição de novas práticas pedagógicas. (CAMACHO; VIEIRA, 2018, p. 449).

Baseado nisso, nota-se a urgência em rever a implementação da política de inclusão escolar para o aluno com deficiência na escola do campo, sobretudo no espaço da realidade ribeirinha. O campo, nesse estudo, se apresenta sob a perspectiva de luta desse povo do campo por uma educação que seja condizente a sua realidade apreendido como um lugar marcado e permeado pela diversidade cultural e multiplicidade de saberes. E "Pensar a educação no contexto ribeirinho implica ter consciência da realidade que circunda o aluno que aí vive, pois esse contexto é o lócus de seu desenvolvimento." (LOBATO, DAVIS, 2019, p. 176)

Os princípios da educação inclusiva permitem oportunidades para que o aluno adquira e demonstre suas habilidades e competências, bem como ocupe, na sociedade, seu lugar como cidadão crítico, conhecedor de seus direitos e promotor social ativo. Isso exige da escola e dos profissionais da educação preparo e constante aperfeiçoamento, pois "a educação não existe fora do território, assim como a cultura, a economia e todas as outras dimensões." (FERNANDES; MOLINA, 2005, p. 29).

Quando essa escola, que esta situada no espaço do campo ribeirinho, recebe indivíduos com necessidades educacionais especiais e oferece condições 
necessárias para seu acesso, permanência e sucesso escolar, ela a reconhece e considera as diferenças e possibilidades de aprendizagem e desenvolvimento dos ser humano, e o espaço social é a própria materialização como parte da existência humana (FERNANDES, 2005) que enriquece seu conhecimento no processo educacional.

Educação especial e educação do campo são distintas e se complementam no que diz respeito a sua construção de lutas, obstáculos e superações para sua concretização. Corrêa (2019) afirma que a Educação Especial e a Educação do Campo apresentam semelhanças e singularidades, principalmente ao ser analisadas as condições de exclusão vividas ao longo da história que as pessoas com deficiência e as populações do campo vem sofrendo no que diz respeito ás politicas publicas nacionais e com muita luta vem superado.

Caiado (2015) reforça ao reafirmar que o histórico brasileiro para com estas duas áreas educacionais é de descaso. Nessa condição, implica em despertar um viés de reflexões críticas sobre os caminhos que vem sendo percorrida no processo de implementação de políticas públicas, ligadas a inclusão escolar do aluno com deficiência no campo, tem sido lenta.

O avanço na legislação deveria criar mecanismos reais de inclusão para as pessoas com deficiência que vivem e estudam no campo de forma a possibilitar a esse aluno vivenciar suas experiências humanas com qualidade social no próprio espaço em que vive, assim como considerados os textos legais - o acesso, a permanência e o sucesso escolar desses alunos deveriam estar representados no panorama educacional atual. Todavia, apesar de todo o arsenal legislativo, a realidade e os dados disponíveis revelam que, para a grande maioria da população, e principalmente na educação do campo, as leis e os procedimentos legais são incoerentes e desconhecidos e, consequentemente, os direitos das pessoas com deficiência continuam sendo violados de inúmeras formas. 


\section{CONSIDERAÇÕES FINAIS}

Com esse estudo constata-se que inclusão, significa acolher, aceitar e valorizar as diferenças a partir do que elas possuem de mais concreto, ou seja, reconhecer o outro como ser humano e oportunizar Ihe vivências sociais, culturais e pessoais permeadas por valores éticos e humanos. (MANTOAN, 2005)

$\mathrm{Na}$ verdade, trata-se de uma ideia que tem como alvo principal a valorização do ser humano em qualquer ambiente que esteja inserido, seja ele urbano ou rural ribeirinho.

E para realizar um estudo voltado para a questão interdisciplinar de duas modalidades de ensino com destaque na educação inclusiva constitui um paradigma educacional fundamentado na concepção de direitos humanos, que conjuga igualdade e diferença como valores indissociáveis, e que avança em relação à ideia de equidade formal ao contextualizar as circunstancias históricas da produção da exclusão dentro e fora da escola.

Permitiu também constatar que incluir pessoas com deficiência na educação do campo ribeirinho é importante, no entanto, evidencia-se que é necessário que haja ressignificações tanto no sistema educacional quanto nas condições do exercício docente para que as diretrizes da educação inclusiva realmente aconteçam como foi estabelecido nos documentos legais. Diante disso, podemos concluir que os aportes legais e teóricos que deveriam garantir a educação escolar universal, gratuita e em condições de equidade, inclusive para os deficientes que moram no campo e estudam nas escolas ribeirinhas, não estão satisfazendo a educação com qualidade.

Assim, como resultado, é possível tomarmos a liberdade de dizer que a Educação Inclusiva significa uma reestruturação no modelo tradicional da escola, bem como a ressignificação da sua prática docente, de forma que remova todas as barreiras para à aprendizagem, formando uma equipe de profissionais humanizados e qualificados que busque formas de interação pedagógica, políticas públicas inclusivas, metodologias diferenciadas e significativas, estratégias de ensino e práticas 
avaliativas que favoreça a construção e o desenvolvimento de uma sociedade inclusiva.

Obviamente não poderemos dá respostas prontas que possam solucionar as incoerências da inclusão para o deficiente na escola do campo, que muitas vezes se esgota nos conceitos e debates. Mas espera-se que o presente artigo possa despertar uma análise crítica nos profissionais da educação e áreas afins sobre o processo de inclusão efetivo aos deficientes que estudam nas escolas ribeirinhas, contribuindo para o debate e a ampliação das reflexões acerca da importância de considerar as necessidades e peculiaridades dessa clientela assegurando uma equidade educacional. Bem como proporcionar o crescimento das discussões de um ambiente educacional menos excludente, que inicialmente implicam numa mudança curricular das escolas, nas condições do exercício docente e posteriormente em práticas inclusivas que apontam para um ensino igualitário e significativo.

\section{REFERÊNCIAS}

ARROYO, Miguel G. Pedagogias Em Movimento - o que temos a aprender dos Movimentos Sociais? Currículo sem Fronteiras, v.3, n.1, pp. 28-49, Jan/Jun 2003. Professor Titular da Universidade Federal de Minas Gerais, Faculdade de Educação, Belo Horizonte, Brasil.

BRASIL. Conselho Nacional de Educação. Câmara de Educação Básica. 2009. Resolução CNE/CEB no 04 de 02 de Outubro de 2009å. Institui diretrizes operacionais para o Atendimento Educacional Especializado na educação básica, modalidade Educação Especial. Lex. Brasília, DF, 2009a.

. Ministério da Educação. Secretaria de Educação Continuada, Alfabetização, Diversidade e Inclusão - SECADI. Educação do Campo: marcos normativos/Secretaria de Educação Continuada, Alfabetização, Diversidade e Inclusão - Brasília: SECADI, 2012. 
, Lei de Diretrizes e Bases da Educação Nacional. Lei nำ.394/96 , de 20 de dezembro de 1996.

- Estatuto da Criança e do Adolescente/ Secretaria especial dos Direitos Humanos; Ministério da Educação. Lei №8.069/90 - Brasília, 2005

. Secretaria da Educação Fundamental. Parâmetros Curriculares Nacionais: Apresentação dos temas transversais e Ética. Brasília: MEC/SEF, 1997.

. Lei Brasileira de Inclusão da Pessoa com Deficiência (Estatuto da Pessoa com Deficiência). № 13.146, DE 6 de Julho de 2015.

BRASÍLIA. A Nova Política de Educação Especial na Perspectiva da Educação Inclusiva. Janeiro de 2008.

CAIADO, K. R. M. Educação especial no campo: uma interface a ser construída. In: BAPTISTA, C. R. (Org.). Escolarização e deficiência: configurações nas políticas de inclusão escolar. São Carlos: Marquezine \& Manzini; ABPEE, 2015.p.75-89.

CAIADO, Katia Regina Moreno; MELETTI, Silvia Márcia Ferreira. EDUCAÇÃO ESPECIAL NA EDUCAÇÃO DO CAMPO: 20 ANOS DE SILÊNCIO NO GT 15. Rev. Bras. Ed. Esp., Marília, v.17, p.93-104, Maio-Ago. 2011. Edição Especial.

CALDART, Isabel Brasil Pereira, Paulo Alentejano e Gaudêncio Frigotto. - Dicionário da Educação do Campo. Rio de Janeiro, São Paulo: Escola Politécnica de Saúde Joaquim Venâncio, Expressão Popular, 2012.

CAMACHO, Rodrigo Simão. O território como categoria da Educação do Campo: no campo da construção/destruição e disputas/conflitos de territórios/territorialidades. Revista Nera (UNESP), 2019.

CAMACHO, Rodrigo Simão. VIEIRA, Jaqueline Machado. Reflexões acerca da educação especial e da educação do campo numa perspectiva inclusiva. In: Interfaces da Educação, Paranaíba, v.9, n.27, p. 443-464, 2018. 
CORRÊA, Rosa Alessandra Rodrigues. Educação Especial nas escolas do campo: uma análise dos indicadores educacionais da rede municipal de ensino de Corumbá MS. 2019. 90 p. Dissertação (Mestrado na Área de Concentração em Educação Social). Programa de Pós-Graduação em Educação - Curso de Mestrado na Área de Concentração em Educação Social da Universidade Federal de Mato Grosso do Sul, Campus do Pantanal, Corumbá, 2019.

DELLA-ROSA. V. A. Etiologia e Prevenção da Deficiência Intelectual. In: Ribeiro, M.J.L.; Della-Rosa, V.A. (Org.). Laboratório Temático de Inclusão Digital e Diversidade: Teoria e Experiências. 1 ed. Maringá-PR: EDUEM, 2010, v. p. 2548. Formação Continuada à Distância de Professores para 0 atendimento Educacional Especializado (Deficiência Física ) - SEESP/ SEED/ MEC- Brasília2007.

GUIMARÃES, Arthur. Inclusão que funciona. IN: Revista Nova Escola. São Paulo: Fundação Victor Civita, 2003. p.43-47.

LAKATOS, Eva Maria; MARCONI, Marina de Andrade. Fundamentos de metodologia científica - 5. ed. - São Paulo : Atlas 2003.

LOBATO, Vivian Silva; DAVIS, Claudia Leme Ferreira. Saberes e profissionalidade de egressos do curso de Pedagogia das Águas: a formação inicial em foco. Educar em Revista, Curitiba, Brasil, v. 35, n. 78, p. 167-185, nov./dez. 2019.

MANTOAN, Maria Tereza Eglér. O direito a diferença na escola. In. Revista Pátio. MEC/FNDE. Ano VII no 32. Novembro/2004 a Janeiro/2005.

MANTOAN, Maria Tereza Egler. A integração de pessoas com deficiência: contribuições para uma reflexão sobre o tema. São Paulo: Memmon/SENAC, 1997.

Maria Teresa Eglér. Ensinando a turma toda, Revista pátio, ano v, oㅡ 20, fevereiro/abril 2005. 
M. T. E. Inclusão escolar: o que é? por quê? como fazer? São Paulo: Moderna, 2003.

M. T. Inclusão Escolar: caminhos e descaminhos, desafios e perspectivas. Revista de Debates. v.4. p. 25-31. Belo Horizonte: Outro Olhar, 2005.

MAZZOTA, Marcos José Silveira. Educação Especial no Brasil: História e políticas públicas. 5 ed. São Paulo: Cortez, 2005.

MOLINA, Mônica Castagna. Brasil. Ministério do Desenvolvimento Agrário. Educação do Campo e Pesquisa: questões para reflexão. - Brasília: Ministério do Desenvolvimento Agrário, 2006.

SASSAKI, Romeu Kazumi. Terminologia sobre deficiência e era da inclusão. 3 ed. Rio de Janeiro: WVA, 1999.

STAINBACK, Susan; STAINBACK, William; LOPES, Magda França (trad.) Inclusão: um guia para educadores. Porto Alegre. Artes Médicas Sul, 2004.

UNESCO. Seminário: Democracia, educação e equidade: Uma agenda para todos. 2019.

Enviado: Julho, 2020.

Aprovado: Agosto, 2020. 